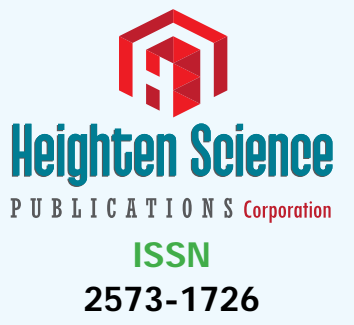

*Address for Correspondence: Baha külünkoğlu, Department of Physiotherapy and Rehabilitation, Faculty of Health Sciences, Yildirim Beyazit University, Ankara, Turkey, Email: anaforoglub@hotmail.com

Submitted: 23 December 2017

Approved: 09 January 2018

Published: 10 January 2018

Copyright: @ 2018 Külünkoğlu B, et al. This is an open access article distributed under the Creative Commons Attribution License which permits unrestricted use, distribution, and reproduction in any medium, provided the original work is properly cited.

Keywords: Hallux valgus; Navicular drop; Quality of life
Research Article

\section{Effect of foot posture on foot-specific health-related quality of life}

\author{
Bahar Külünkoğlu1*, Yasemin Akkubak ${ }^{1}$ and Afra Alkan ${ }^{2}$ \\ 'Department of Physiotherapy and Rehabilitation, Faculty of Health Sciences, Yildirim Beyazit \\ University, Ankara, Turkey \\ ${ }^{2}$ Department of Biostatistics and Medical Informatics, Institute of Health Sciences, Yildirim \\ Beyazit University, Ankara, Turkey
}

\section{Abstract}

The purpose of this study was to determine the relationship between Navicular drop (ND) and Hallux valgus (HV) angles and their effects on foot-specific health related quality of life. Sixty female patients with bilateral HV aged between 32-60 participated in this study. The patients with the HV deformity degree of " 2 " or " 3 " according to the Manchester scale were included.

$\mathrm{HV}$ angle were obtained from standing (weight bearing) bilateral antero-posterior radiographs. $\mathrm{HV}$ angle (A angle), intermetatarsal angle (B angle), hallux interphalangeal angle ( $\mathrm{C}$ angle) were measured. Subtalar pronation was measured the navicular drop (ND) test. ND test were performed for both feet and recorded in millimeters. Foot-specific health related quality of life was measured using the Manhester-Oxford Foot Questionnaire (MOFQ).

There was a strong positive correlation between the ND qtest and the angles $A, B$, and $C$ for the right foot (rho $=0.749,0.761$ and $0.749 p<0.001$, respectively,). There was a strong positive correlation between the MOFQ subscales and the angles $A, B$, and $C$ for the right foot $(p<0.001)$. There was a strong positive correlation between the MOFQ subscales and the angles $A, B$, and $C$ for the right foot $(p<0.001)$.

In conclusion, there were relationship between ND, HV angular severity and foot-specific health related quality of life. As the HV angular severity increased, there was greater drop in the navicula and reduction in quality of life.

\section{Introduction}

Hallux valgus (HV) is characterized as a symptomatic condition presenting lateral deviation of the great toe and medial deviation of the first metatarsal head [1]. HV is also a progressive and common foot deformity [2]. Estimated prevalence of $\mathrm{HV}$ in the general population varies between $21 \%$ and $65 \%$ [3-5]. Epidemiological studies have reported that women are substantially more likely to develop HV as compared with men $[4,6,7]$. Nguyen and colleagues reported that prevalence of $\mathrm{HV}$ in females and males were $58 \%$ and $25 \%$, respectively [7]. Another study reported that the prevalence of $\mathrm{HV}$ in females was 2.3 times more than the estimate for males [8].

The certain cause of HV is still unknown. However, many research have defined the multifactorial origin of HV. Unsuitable footwear, excessive weight-bearing as extrinsic factors and age, genetics, female gender, joint hyper mobility, ligamentous laxity, specific foot deformities (pes planus, metatarsal primus varus) as intrinsic factors lead to the development of HV $[9,10]$.

Navicular drop (ND) is a chronic condition characterized by inadequate support of the medial longitudinal arch (MLA) and extreme subtalar joint pronation of the foot [11,12]. Previous studies have reported that collapse of MLA and an excessively pronated foot is associated with $\mathrm{HV}[9,13]$. 
Foot pain and impaired functional status in $\mathrm{HV}$ are associated with the quality of life $[3,14]$. Deformities related to HV can cause altered gait parameters, foot pain and may ultimately reduce the physical activities and quality of life of the patients $[15,16]$. Previous studies have also argued that people with HV demonstrate significantly lower scores on foot - specific health related quality of life $[3,14,17]$.

Accordingly, the purpose of this study was to determine the relationship between $\mathrm{ND}$ and $\mathrm{HV}$ angles and their effects on foot - specific health related quality of life.

\section{Method}

This study was conducted at Yildirim Beyazit University Atatürk Education and Research Hospital, Department of Physical Therapy and Rehabilitation and was approved Ankara Yildirim Beyazit University ethical committee, Ankara, Turkey (no:575/12). Informed consents were obtained from all patients.

\section{Participants}

Sixty female patients with bilateral HV aged between 32-60 enrolled in this study. The patients with the HV deformity degree of " 2 " or " 3 " according to the Manchester scale were included [18]. Patients with mental or cognitive impairment, systemic disease, any history of surgery and orthopedic problem of lower extremity were excluded. Demographic data of participants (age, height, weight etc.) were recorded.

\section{Measurements}

\section{- Manchester Scale}

Manchester scale was developed to determine the severity of HV deformity. In this scale, the severity of $\mathrm{HV}$ deformity are divided into four groups by using standardized four photographs of feet: 0 'no deformity', 1 'mild deformity', 2 'moderate deformity', and 3 'severe deformity' [18]. The validity and reliability of this scale was previously performed [19].

\section{- HNAngle}

HV angle were obtained from standing (weight bearing) bilateral antero-posterior radiographs. HV angle (A angle), intermetatarsal angle (B angle), hallux interphalangeal angle ( $\mathrm{C}$ angle) were measured.

A angle is the angle between the longitudinal axis of the first metatarsal bone and that of the proximal phalanx. B angle is between the longitudinal axis of the first and second metatarsal bones. $\mathrm{C}$ angle forms the intersection of two longitudinal axis of distal with proximal phalanx [10].

\section{- Navicular height}

The navicular drop (ND) test is the clinical measure of subtalar pronation. Menz et al. reported that measurement of NH with ND test to be significantly associated with the corresponding radiographic measure (Pearson $r=0.79$ ) [19]. Initially, the foot was in the subtalar neutral position and the height of the navicular tuberosity from the ground was measured using a ruler in sitting position. Then, the subjects were asked to stand with a relaxed foot. The distance of navicula was measured again. The difference between two measures was calculated. ND test were performed for both feet and recorded in millimeters $[20,21]$.

\section{- Manhester-Oxford Foot Questionnaire (MOFQ)}

Foot - specific health related quality of life was measured using the MOFQ. The MOFQ contains three categories of quality of life; pain, walking/standing and social interaction. It consists of 16 items which are scored using a Likert scale and each item scored between $\mathrm{o}$ and 4 . Each three categories is scored between 0 and 100 and higher scores state most severe conditions [22]. 


\section{Statistical Analysis}

Distribution of continuous variables such as age, BMI (Body Mass Index), the result of the ND test in the study were examined by Shapiro-Wilk test and normality graphs. The normally distributed variables were shown as mean \pm standard deviation $(\mathrm{X} \pm \mathrm{SD})$ and minimum-maximum, while the other continuous variables were shown as $\mathrm{X} \pm \mathrm{SD}$ and median (min-max). Dominant side was shown as count (\%).

The relationship between the ND test, radiological measurements and MOFQ scores were assessed by the Spearman rho coefficient. Statistical significance level was accepted as $\mathrm{p}<0.05$. IBM SPSS Statistics 21.0 (IBM Corp. released 2012. IBM SPSS Statistics for Windows, version 21.0, Armonk, NY: IBM Corp.) Program was used for all statistical analysis and calculations.

\section{Results}

The demographic characteristics of patients were shown in Table 1 . The mean age and body mass index (BMI) of the patients were $48.02 \pm 7.37$ years and $27.20 \pm 3.08 \mathrm{~kg} /$ $\mathrm{m}^{2}$, respectively. The dominant side of $85.0 \%$ of the patients was right (Table 1 ).

The mean ND test of the patients was calculated as $6.29 \pm 1.17 \mathrm{~mm}$ in the right foot and $6.22 \pm 1.18 \mathrm{~mm}$ in the left foot. The mean an angle was $20.57 \pm 4.27$ degrees for the right foot and $20.92 \pm 3.62$ degrees for the left foot. The results of the other radiological measurements and MOFQ scores are given in table 2.

\begin{tabular}{|c|c|c|c|}
\hline \multicolumn{2}{|c|}{ Demographic characteristics } & $X \pm S D n=60$ & Min-Max \\
\hline \multicolumn{2}{|c|}{ Age (years) } & $48.02 \pm 7.37$ & $32-60$ \\
\hline \multicolumn{2}{|c|}{ Height (m) } & $1.56 \pm 0.05$ & $1.45-1.68$ \\
\hline \multicolumn{2}{|c|}{ Weight (kg) } & $66.12 \pm 6.50$ & $47-81$ \\
\hline \multirow{2}{*}{\multicolumn{2}{|c|}{$\mathrm{BMI}\left(\mathrm{kg} / \mathrm{m}^{2}\right)$}} & $27.20 \pm 3.08$ & 20.61-33.32 \\
\hline & & $\mathrm{N}$ & $\%$ \\
\hline \multirow{2}{*}{ Dominant side } & Right & 51 & 85.0 \\
\hline & Left & 9 & 15.0 \\
\hline & & $\mathrm{N}$ & $\%$ \\
\hline \multirow{2}{*}{ Manchester Scale } & Right $(2 / 3)$ & $30 / 30$ & $50.0 / 50.0$ \\
\hline & Left $(2 / 3)$ & $28 / 32$ & $46.7 / 53.3$ \\
\hline
\end{tabular}

$\mathrm{X} \pm \mathrm{SD}$ : mean \pm standard deviation, Min: minimum, Max: maximum, BMI: Body mass index, m: metre, kg: kilogram, \%: percent.

Table 2: The results of radiological measurements of hallux valgus angle, Manchester-Oxford Questionnaire Subscales and Navicular Drop Test.

\begin{tabular}{|c|c|c|}
\hline $\begin{array}{l}\text { Evaluation of the clinical characteristics of } \\
\text { foot }\end{array}$ & Right $n=60$ & Left $n=60$ \\
\hline ND test $(\mathrm{mm})[\mathrm{X} \pm \mathrm{SD}]$ & $6.29 \pm 1.17$ & $6.22 \pm 1.18$ \\
\hline Median (min-max) & $6(4-8)$ & $6(4-8)$ \\
\hline A angle $[\mathrm{X} \pm \mathrm{SD}]$ & $20.57 \pm 4.27$ & $20.92 \pm 3.62$ \\
\hline Median (min-max) & $20(10-31)$ & $20(12-30)$ \\
\hline$B$ angle $[\mathrm{X} \pm \mathrm{SD}]$ & $17.23 \pm 2.24$ & $17.17 \pm 1.87$ \\
\hline Median (min-max) & $17(13-22)$ & $17(14-22)$ \\
\hline $\mathrm{C}$ angle $[\mathrm{X} \pm \mathrm{SD}]$ & $10.85 \pm 2.99$ & $10.85 \pm 2.52$ \\
\hline Median (min-max) & $10(5-22)$ & $10(6-20)$ \\
\hline MOFQ-W $[X \pm S D]$ & $50.27 \pm 4.29$ & $51.64 \pm 4.20$ \\
\hline Median (min-max) & $51.8(44.0-55.4)$ & $53.8(44.0-58.9)$ \\
\hline MOFQ-P $[X \pm S D]$ & $55.77 \pm 3.48$ & $56.3 \pm 3.16$ \\
\hline Median (min-max) & $57.6(50.0-60.1)$ & $58.0(51.0-60.0)$ \\
\hline MOFQ-S [X $\pm S D]$ & $45.6 \pm 3.17$ & $46.06 \pm 3.55$ \\
\hline Median (min-max) & $46.1(40.0-49.9)$ & $47.9(40.0-52.0)$ \\
\hline
\end{tabular}

ND: Navicular Drop, $\mathrm{X} \pm \mathrm{SD}$ : mean \pm standard deviation, Min: minimum, Max: maximum, $\mathrm{A}$ angle: $\mathrm{HV}$ angle, $\mathrm{B}$ angle: intermetatarsal angle, C angle: hallux interphalangeal angle, MOFQ-W: Manchester-Oxford Foot QuestionnaireWalking Subscale Score, MOFQ-P: Manchester-Oxford Foot Questionnaire-Pain Subscale Score, MOFQ-S: Manchester-Oxford Foot Questionnaire- Social Subscale Score. 
There was a strong positive correlation between the ND test and the angles $\mathrm{A}, \mathrm{B}$, and $\mathrm{C}$ for the right foot (rho $=0.749,0.761$ and $0.749 \mathrm{p}<0.001$, respectively,). For the left foot, ND test was positively correlated with the A and B angles but weaker than the right foot (rho $=0.644$ and 0.654 , respectively, $\mathrm{p}<0.001$ ). There was a moderately positive correlation between the ND test and $\mathrm{C}$ angle (Table 3 ).

There was a strong positive correlation between the MOFQ subscales and the angles $\mathrm{A}, \mathrm{B}$, and $\mathrm{C}$ for the right foot ( $\mathrm{p}<0.001$ ). For the left foot, MOFQ subscales was positively correlated with the A and B angles $(p<0.001)$ but was moderately correlated $C$ angle (Table 4).

\section{Discussion}

Several authors have suggested that the pressure exerted on medial side of the foot and capsule of the first metatarsophalangeal joint may cause development and progression of HV deformity $[12,23]$. Therefore, we aimed to determinate how much the amount of navicular drop would affect the HV angular severity and foot- specific health related quality of life in this study.

Table 3: Relationship between Navicular Drop test and radiological measurements, Manchester-Oxford Questionnaire Subscales.

\begin{tabular}{|c|c|c|}
\hline \multicolumn{3}{|c|}{ Navicular Drop Test (mm) } \\
\hline Correlations & Right $n=60$ & Left $n=60$ \\
\hline \multicolumn{3}{|l|}{ A angle } \\
\hline rho & 0.749 & 0.644 \\
\hline $\mathrm{p}$ & $<0.001^{\star \star}$ & $<0.001^{\star \star}$ \\
\hline \multicolumn{3}{|l|}{ B angle } \\
\hline rho & 0.761 & 0.651 \\
\hline $\mathrm{p}$ & $<0.001$ ** & $<0.001^{\star *}$ \\
\hline \multicolumn{3}{|l|}{ C angle } \\
\hline rho & 0.749 & 0.457 \\
\hline $\mathrm{p}$ & $<0.001^{\star \star}$ & $<0.001^{* *}$ \\
\hline \multicolumn{3}{|l|}{ MOFQ-W } \\
\hline rho & 0.547 & 0.345 \\
\hline $\mathrm{p}$ & $<0.001^{\star \star}$ & $0.007 *$ \\
\hline \multicolumn{3}{|l|}{ MOFQ-P } \\
\hline rho & 0.609 & 0.416 \\
\hline $\mathrm{p}$ & $<0.001^{\star \star}$ & $0.001^{*}$ \\
\hline \multicolumn{3}{|l|}{ MOFQ-S } \\
\hline rho & 0.509 & 0.540 \\
\hline $\mathrm{p}$ & $<0.001^{\star \star}$ & $<0.001^{\star *}$ \\
\hline
\end{tabular}

$\mathrm{mm}$ : milimeter, $\mathrm{A}$ angle: $\mathrm{HV}$ angle, $\mathrm{B}$ angle: intermetatarsal angle, $\mathrm{C}$ angle: hallux interphalangeal angle, MOFQ-W: Manchester-Oxford Foot Questionnaire-Walking Subscale Score, MOFQ-P: Manchester-Oxford Foot QuestionnairePain Subscale Score, MOFQ-S: Manchester-Oxford Foot Questionnaire- Social Subscale Score, ${ }^{\star *}: p<0.001, *$ : $p<0.05$

Table 4: Relationship between Manchester-Oxford Questionnaire Subscales and radiological measurements.

\begin{tabular}{|c|c|c|c|c|c|}
\hline \multirow{2}{*}{\multicolumn{2}{|c|}{$\begin{array}{c}\text { Radiological } \\
\text { Measurements }\end{array}$}} & & \multicolumn{3}{|c|}{ Manchester-Oxford Questionnaire Subscales } \\
\hline & & & MOFQ-W & MOFQ-P & MOFQ-S \\
\hline \multirow{4}{*}{ A angle } & \multirow{2}{*}{ Right } & rho & 0.529 & 0.572 & 0.562 \\
\hline & & $\mathrm{p}$ & $<0.001^{\star *}$ & $<0.001^{\star \star}$ & $<0.001^{\star \star}$ \\
\hline & \multirow{2}{*}{ Left } & rho & 0.363 & 0.507 & 0.511 \\
\hline & & $\mathrm{p}$ & $<0.001^{\star \star}$ & $<0.001^{* *}$ & $<0.001^{\star \star}$ \\
\hline \multirow{4}{*}{ B angle } & \multirow{2}{*}{ Right } & rho & 0.551 & 0.529 & 0.517 \\
\hline & & $\mathrm{p}$ & $<0.001^{\star \star}$ & $<0.001^{\star \star}$ & $<0.001^{\star *}$ \\
\hline & \multirow{2}{*}{ Left } & rho & 0.446 & 0.554 & 0.516 \\
\hline & & $\mathrm{p}$ & $<0.001^{\star *}$ & $<0.001^{\star *}$ & $<0.001^{\star *}$ \\
\hline \multirow[t]{4}{*}{ C angle } & \multirow{2}{*}{ Right } & rho & 0.486 & 0.510 & 0.468 \\
\hline & & $\mathrm{p}$ & $<0.001^{\star \star}$ & $<0.001^{\star *}$ & $<0.001^{\star *}$ \\
\hline & \multirow{2}{*}{ Left } & rho & 0,256 & 0,473 & 0.402 \\
\hline & & $\mathrm{p}$ & $0,046^{*}$ & $0.001 *$ & $<0.001 * \star$ \\
\hline
\end{tabular}

A angle: $\mathrm{HV}$ angle, $B$ angle: intermetatarsal angle, $\mathrm{C}$ angle: hallux interphalangeal angle, MOFQ-W: Manchester-Oxford Foot Questionnaire-Walking Subscale Score, MOFQ-P: Manchester-Oxford Foot Questionnaire-Pain Subscale Score, MOFQ-S: Manchester-Oxford Foot Questionnaire- Social Subscale Score, $* *: p<0.001, *: p<0.05$ 
It was suggested that the ND is correlated with foot pronation. Furthermore, the ND measurement is a practical technic for understanding the biomechanical relationship between the foot deformity and MLA structures [12]. The normal value of ND test was accepted $6 \mathrm{~mm}$, value of $9 \mathrm{~mm}$ or more was considered high and values less than 6 mm were considered low [24,25]. In our study, the mean ND test results was found $6.29 \pm 1.17 \mathrm{~mm}$ in right foot and $6.22 \pm 1.18 \mathrm{~mm}$ in left foot. Although, the mean ND test results was within normal limits, HV angular severity and ND test scores were positively correlated. Consequently, as the HV angular severity increased, there was greater drop in the navicula, and the amount of foot pronation was increased.

Komeda et al., have used two-dimensional coordinate system to perform the medial longitudinal arch measurements [26]. However, any correlation was not found between $\mathrm{HV}$ angular severity and navicular height, it was indicated that the main points of flattening of the foot in patients with HV was the dropping of the navicula. They measured the amount of NH in the weight bearing position whereas the difference of navicular height was taken in weight bearing and non-bearing positions in present study. According to our study, the amount navicular displacement in patients with HV is influential on HV angular severity.

To date, many patient- reported questionnaires have been used to evaluate the quality of life in patients with HV $[3,14,22]$. Abhishek et al. have investigated whether $\mathrm{HV}$ and big toe pain associated with imparied quality of life. In this study, generic health assessment instrument was performed to question the quality of life [14]. It was reported that the patients with HV and big toe pain have demonstreated lower quality of life. Menz et al., aimed to investigate the effect of HV severity on general and FootSpecific Health-Related Quality of Life. Medical Outcomes Study Short Form 36 (SF36) and Manchester Foot Pain and Disability Index (FPDI) were used to determinate quality of life. In parallel with our study, as the HV angular severity increased, there was reduction in foot-specific general health related quality of life [3].

MOFQ was developed to evaluate outcome maseure for HV surgery [22]. It was aimed to assess minimally important change and responsiveness for the MOFQ and compare with SF-36 and American Orthopaedic Foot \& Ankle Society(AOFAS) measurements following HV surgery by Dowson et al. Consequently, MOFQ and AOFAS have indicated excellent responsiveness which were superior to SF-36. Furthermore, MOFQ slightly greater than the AOFAS [27].

Taspinar et al. have evaluated the quality of life with SF-36 in patients with pes planus. It has been indicated that as the plantar pressure increases, the quality of life decreases [28]. ND test was used to evaluate navicular height in patients with metatarsal head pain by González-Sánchez et al. [29]. In addition to, Foot Health Status Questionnaire (FHSQ) was performed to measure the quality of life related to foot health. It was obtained modarete to strong relationship between ND test and FHSQ. In the same line, in our study, a moderate correlation was found between ND test and MOFQ. Our study is the first study investigating the relationship between ND with ND test, HV angular severity with radiological measurement and foot-specific health related quality of life with MOFQ.

In conclusion, there were relationship between ND, HV angular severity and footspecific health related quality of life. As the HV angular severity increased, there was greater drop in the navicula and reduction quality of life. Patients with HV should be evaluated for ND. Pes planus exercises should be added to their exercise programs.

\section{References}

1. Ferrari J, Eiff P, Grayzel J. Hallux valgus deformity (bunion). Consultado el. 2014; 22.

2. Mortka K, Lisiński P. Hallux valgus-a case for a physiotherapist or only for a surgeon? Literature review. J Phys Ther Sci. 2015; 27: 3303-3307. Ref.: https://goo.gl/BtCpMH 
3. Menz HB, Roddy E, Thomas E, Croft PR. Impact of hallux valgus severity on general and foot-specific health-related quality of life. Arthritis care \& research. 2011; 63:396-404. Ref.: https://goo.gl/q27sRq

4. Dunn J, Link C, Felson D, Crincoli M, Keysor J, et al. Prevalence of foot and ankle conditions in a multiethnic community sample of older adults. Am J Epidemiol. 2004; 159: 491-498. Ref.: https://goo.gl/c4g638

5. Cho N, Kim S, Kwon DJ, Kim H. The prevalence of hallux valgus and its association with foot pain and function in a rural Korean community. J Bone Joint Surg Br. 2009; 91: 494-498. Ref.: https://goo.gl/FbR5Ts

6. Roddy $E$, Zhang $W$, Doherty M. Prevalence and associations of hallux valgus in a primary care population. Arthritis Rheum. 2008; 59: 857-862. Ref.: https://goo.gl/ot6Ncj

7. Nguyen US, Hillstrom HJ, Li W, Dufour AB, Kiel DP, et al. Factors associated with hallux valgus in a population-based study of older women and men: the MOBILIZE Boston Study. Osteoarthritis and cartilage. 2010; 18: 41-46. Ref.: https://goo.gl/966pAf

8. Nix S, Smith M, Vicenzino B. Prevalence of hallux valgus in the general population: A systematic review and meta-analysis. J Foot Ankle Res. 2010; 3: 21. Ref.: https://goo.gl/7mtzJe

9. Perera A, Mason L, Stephens M. The pathogenesis of hallux valgus. The Journal of Bone \& Joint Surgery. 2011; 93: 1650-1961. Ref.: https://goo.gl/1StQJC

10. Coughlin MJ, Jones CP. Hallux valgus: demographics, etiology, and radiographic assessment. Foot Ankle Int. 2007; 28: 759-777. Ref.: https://goo.gl/Y4VHNT

11. Snook AG. The relationship between excessive pronation as measured by navicular drop and isokinetic strength of the ankle musculature. Foot Ankle Int. 2001; 22: 234-240. Ref.: https://goo.gl/sZREBU

12. Nam KS, Kwon JW, Kwon OY. The relationship between activity of abductor hallucis and navicular drop in the one-leg standing position. Journal of physical therapy science. 2012; 24: 1103-1106. Ref.: https://goo.gl/n53YNc

13. Steinberg N, Finestone A, Noff M, Zeev A, Dar G. Relationship between lower extremity alignment and hallux valgus in women. Foot \& ankle international. 2013; 34: 824-831. Ref.: https://goo.gl/2ccusV

14. Abhishek A, Roddy E, Zhang W, Doherty M. Are hallux valgus and big toe pain associated with impaired quality of life? A cross-sectional study. Osteoarthritis and Cartilage. 2010; 18: 923-926. Ref.: https://goo.gl/XNbGEz

15. Nix SE, Vicenzino BT, Smith MD. Foot pain and functional limitation in healthy adults with hallux valgus: a cross-sectional study. BMC Musculoskelet Disord. 2012; 13: 197. Ref.: https://goo.gl/m7NMqc

16. Nix SE, Vicenzino BT, Collins NJ, Smith MD. Gait parameters associated with hallux valgus: a systematic review. J Foot Ankle Res. 2013; 6: 9. Ref.: https://goo.gl/pDymvW

17. Saro C, Jensen I, Lindgren U, Felländer-Tsai L. Quality-of-life outcome after hallux valgus surgery. Qual Life Res. 2007; 16: 731-738. Ref.: https://goo.gl/cbyJhY

18. Garrow AP, Papageorgiou A, Silman AJ, Thomas E, Jayson MI, et al. The grading of hallux valgus: the Manchester Scale. J Am Podiatr Med Assoc. 2001; 91: 74-78. Ref.: https://goo.gl/K8X91d

19. Menz HB, Munteanu SE. Radiographic validation of the Manchester scale for the classification of hallux valgus deformity. Rheumatology (Oxford). 2005; 44: 1061-1066. Ref.: https://goo.gl/iLxPhA

20. Loudon JK, Jenkins W, Loudon KL. The relationship between static posture and ACL injury in female athletes. Journal of Orthopaedic \& Sports Physical Therapy. 1996; 24: 91-97. Ref.: https://goo.gl/uobH5L

21. Vinicombe A, Raspovic A, Menz HB. Reliability of navicular displacement measurement as a clinica indicator of foot posture. J Am Podiatr Med Assoc. 2001; 91: 262-268. Ref.: https://goo.gl/qG5KKS

22. Dawson J, Coffey J, Doll H, Lavis G, Cooke P, et al. A patient-based questionnaire to assess outcomes of foot surgery: validation in the context of surgery for hallux valgus. Qual Life Res. 2006; 15: 1211 1222. Ref.: https://goo.gl/sKjJKh

23. Glasoe WM, Nuckley DJ, Ludewig PM. Hallux valgus and the first metatarsal arch segment: a theoretical biomechanical perspective. Phys Ther. 2010; 90: 110-120. Ref.: https://goo.gl/bz9t3z

24. Mueller M, Host J, Norton B. Navicular drop as a composite measure of excessive pronation. J Am Podiatr Med Assoc. 1993; 83: 198-202. Ref.: https://goo.gl/ZU1Si1 
25. Woodford-Rogers B, Cyphert L, Denegar CR. Risk factors for anterior cruciate ligament injury in high school and college athletes. J Athl Train. 1994; 29: 343. Reg.: https://goo.gl/ut64F4

26. Komeda T, Tanaka Y, Takakura Y, Fujii T, Samoto N, et al. Evaluation of the longitudinal arch of the foot with hallux valgus using a newly developed two-dimensional coordinate system. Journal of orthopaedic science. 2001; 6: 110-118. Ref.: https://goo.gl/9Bb52t

27. Dawson J, Doll H, Coffey J, Jenkinson C. Responsiveness and minimally important change for the Manchester-Oxford foot questionnaire (MOXFQ) compared with AOFAS and SF-36 assessments following surgery for hallux valgus. Osteoarthritis and cartilage. 2007; 15: 918-931. Ref.: https://goo.gl/QrSzLk

28. Taspinar O, Kabayel DD, Ozdemir F, Tuna H, Keskin Y, et al. Comparing the efficacy of exercise, internal and external shoe modification in pes planus: A clinical and pedobarographic study. J Back Musculoskelet Rehabil. 2017; 30: 255-263. Ref.: https://goo.gl/z5VB4Q

29. González-Sánchez M, Velasco-Ramos E, Muñoz MR, Cuesta-Vargas Al. Relationship between patient-reported outcome measures (PROM) and three measures of foot-ankle alignment in patients with metatarsal head pain: a cross-sectional study. J Foot Ankle Res. 2016; 9: 49. Ref.: https://goo.gl/Fy8b22 